\title{
Successful Salvage Chemotherapy with Streptozocin in a Patient with Mediastinal Atypical Carcinoid Tumor Who Had Relapsed after Various Prior Therapies
}

\author{
Toshirou Fukushima $^{a} \quad$ Daisuke Gomi $^{a} \quad$ Noriko Seno $^{\mathrm{a}, \mathrm{b}}$ Takahiko Gibo ${ }^{\mathrm{a}, \mathrm{c}}$

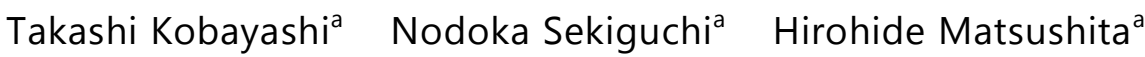 \\ Yoshiko Kasahara $^{d}$ Keiko Mamiya $^{a}$ Tomonobu Koizumi ${ }^{a}$ \\ ${ }^{a}$ Department of Comprehensive Cancer Therapy, Shinshu University School of Medicine, \\ Matsumoto, Japan; ${ }^{b}$ Division of Hematology, Department of Internal Medicine, Shinshu \\ University School of Medicine, Matsumoto, Japan; ${ }^{C}$ Department of Dentistry and Oral \\ Surgery, Shinshu University School of Medicine, Matsumoto, Japan; ${ }^{d}$ Department of \\ Anesthesiology and Resuscitology, Shinshu University School of Medicine, \\ Matsumoto, Japan
}

\section{Keywords}

Multiple endocrine neoplasia type $1 \cdot$ Chemotherapy $\cdot$ Everolimus · Sunitinib $\cdot$ Mediastinal tumor

\begin{abstract}
Pulmonary neuroendocrine tumors are rare, and there have been very few reports regarding optimal chemotherapeutic regimens. Two molecular targeted agents, everolimus and sunitinib, have recently been shown to provide an additional treatment benefit for pulmonary neuroendocrine tumors. However, little information is available regarding the usefulness of streptozocin chemotherapy. Here, we encountered a case of relapsed and refractory mediastinal atypical carcinoid tumor associated with multiple endocrine neoplasia type 1 for various cytotoxic and molecular targeted agents. The patient showed a good response to streptozocin monotherapy. We describe the case and review streptozocin chemotherapy in patients with pulmonary neuroendocrine tumors.




\section{Introduction}

Neuroendocrine tumors (NETs) are a family of neoplasms that can arise from neuroendocrine cells of most organs in the body, including the pancreas, gastrointestinal tract, lung, and thymus [1]. Pulmonary NETs include low- and intermediate-grade tumors, designated as typical and atypical carcinoid (AC) tumors, respectively. Typical and atypical tumors account for 15.1 and $2.5 \%$ of pulmonary NETs, respectively [2], but only $1 \%$ of pulmonary tumors [2]. Although surgery is the treatment of choice for patients with resectable lung carcinoid tumors, the prognosis of metastatic disease is poor: the median survival is 16 months for cases with metastasis in the lung and 40 months for those with such lesions in the thymus [1]. Based on 2 large placebo-controlled phase III studies, new molecular targeted agents, sunitinib (multiple tyrosine kinase inhibitor) [3] and everolimus (mTOR inhibitor) [4-6], have recently been approved for the treatment of NETs. In addition, Fazio et al. [5] performed a subgroup analysis and reported that everolimus improved progression-free survival in advanced lung NETs by 2.4-fold compared with the placebo group. However, current systemic treatment options are of limited efficacy, and little information is available regarding patients with metastatic lung NETs [5-7].

Streptozocin (STZ) has been used for up to 30 years as a single agent or in combination therapy for the treatment of NETs in the pancreas and digestive tracts [8-15]. A study pooling reports of STZ monotherapy showed a response rate of $42 \%$ [8]. Although there have been careful clinical evaluations of the usefulness of STZ in pancreatic NET [8-15], little information is available regarding the clinical benefit in patients with lung NET $[5,10]$. We encountered a case of metastatic and relapsed mediastinal AC tumor associated with multiple endocrine neoplasia type 1 . The patient had been heavily treated with several cytotoxic agents and 2 molecular targeted agents over 5 years, but developed left pleural metastasis and pleural effusion. Salvage chemotherapy with STZ monotherapy was effective and disease control was observed over 6 months. Here, we describe a rare case of mediastinal AC tumor along with a review of the relevant literature.

\section{Case Presentation}

A 39-year-old man was admitted to our hospital in 2011 because of slowly progressing left chest pain over a few years. Chest radiography and computed tomography (CT) showed a large anterior mediastinal mass. Histological analysis by percutaneous CT-guided biopsy revealed AC tumor, and the Ki67 labeling index was 10\% (Fig. 1). Simultaneously, hypercalcemia $(\mathrm{Ca}, 11.7 \mathrm{mg} / \mathrm{dL})$ and parathyroid gland adenoma were present. A diagnosis of multiple endocrine neoplasia type 1 was made because of his family history and the results of genetic screening. As the mediastinal tumor was considered to be locally advanced and unresectable, the patient was initially treated with 4 cycles of cisplatin and etoposide chemotherapy. Partial response was observed after the chemotherapy, but the disease remained unresectable. After the relapse of the mediastinal tumor, various cytotoxic chemotherapies were repeated but failed to reduce the tumor size. He developed carcinoid syndrome (slight fever and diarrhea), and octreotide long-acting repeatable (LAR) was initiated in 2014, which resulted in improvement of the symptoms. Subsequently, radiographic stability was obtained by a combination of octreotide LAR and everolimus, followed by sunitinib therapy over 2.5 years. However, re-growth of the mediastinal mass was observed and left pleural effusion was present for the first time in 2016. The results of chest radiography and CT are 
shown in Figure 2. Cytological examination of left pleural effusion was consistent with pleural dissemination of the AC tumor. STZ administration was begun at a dose of $40 \mathrm{mg} / \mathrm{m}^{2}$ per day on days $1-5$, every 5 weeks. Serial chest radiographs following 4 cycles of STZ treatment indicated significant reductions in left pleural effusion and the size of the mediastinal masses (Fig. 3). During treatment, thoracocentesis was not performed. In addition, no significant adverse events, including hematological or nonhematological toxicities, were observed during 4 cycles of STZ monotherapy.

\section{Discussion}

We reported a case of metastatic mediastinal AC tumor successfully treated with STZ monotherapy that had relapsed after heavy treatment with several cytotoxic agents and 2 available molecular targeted agents. Based on our experience, we emphasize the use of STZbased chemotherapy in patients with advanced and metastatic pulmonary NET as a novel therapy.

Several studies in patients with NET of the pancreas and digestive tract indicated response rates to chemotherapy with STZ in combination with 5-FU or doxorubicin of 27.7$42.0 \%$ [8-14]. To our knowledge, there have been no reports focusing on the efficacy of STZbased chemotherapy in lung NET. Krug et al. [10] reported partial responses to STZ-based chemotherapy in 2 of 7 nonpancreatic NET cases (28.6\%) compared to 19 of 56 pancreatic NET cases (33.9\%). These results suggested that the response rate was slightly lower in nonpancreatic NET compared with pancreatic NET. However, the nonpancreatic NET sample size was too small, and it was unclear how many cases of lung NET were included in the nonpancreatic group. Thus, little information or clinical experience is available regarding the efficacy of STZ-based chemotherapy in pulmonary NET.

With regard to pancreatic NET, a randomized trial indicated the superiority of STZ combined with 5-FU as compared to STZ monotherapy [9, 14, 15]. The toxicities in STZ-based chemotherapy were well tolerated in previous reports [9-15]. Although the present case was treated successfully with STZ monotherapy and there were no specific toxicities, it was necessary to combine some cytotoxic agents with STZ for additive clinical benefit. NETs have been regarded as relatively rare neoplasms, but the numbers of patients with NETs are increasing in the USA [1], Europe [16], and Japan [17, 18]. In particular, the increase in lung NET is remarkable [1]. In proportion to the increase, it is speculated that advanced and/or metastatic lung NET patients could increase in number. Further clinical experience and studies are required to determine the usefulness of STZ-based chemotherapy for lung NET. Our case indicated that STZ-based chemotherapy is an important and a novel therapeutic choice for advanced and/or metastatic lung NET, although 2 molecular targeted agents combined with or without octreotide LAR were available.

In conclusion, the present case emphasized that STZ is a useful agent for metastatic mediastinal AC tumor refractory to previous chemotherapies in Japanese patients. Thymic and metastatic carcinoid tumors are extremely rare in clinical practice. We should be aware that treatment with STZ may be an optimal therapeutic choice in patients with pulmonary NET. 


\section{Statement of Ethics}

Written informed consent was obtained from the patient for the publication of this case report.

\section{Disclosure Statement}

The authors report no potential conflicts of interest.

\section{References}

1 Yao JC, Hassan M, Phan A, Dagohoy C, Leary C, Mares JE, Abdalla EK, Fleming JB, Vauthey JN, Rashid A, Evans DB: One hundred years after "carcinoid": epidemiology of and prognostic factors for neuroendocrine tumors in 35,825 cases in the US. J Clin Oncol 2008;26:3063-3072.

-2 Asamura H, Kameya T, Matsuno Y, Noguchi M, Tada H, Ishikawa Y, Yokose T, Jiang SX, Inoue T, Nakagawa K, Tajima K, Nagai K: Neuroendocrine neoplasms of the lung: a prognostic spectrum. J Clin Oncol 2006;24:70-76.

-3 Raymond E, Dahan L, Raoul JL, Bang YJ, Borbath I, Lombard-Bohas C, Valle J, Metrakos P, Smith D, Vinik A, Chen JS, Hörsch D, Hammel P, Wiedenmann B, Van Cutsem E, Patyna S, Lu DR, Blanckmeister C, Chao R, Ruszniewski P: Sunitinib malate for the treatment of pancreatic neuroendocrine tumors. N Engl J Med 2011;364:501-513.

-4 Pavel ME, Hainsworth JD, Baudin E, Peeters M, Hörsch D, Winkler RE, Klimovsky J, Lebwohl D, Jehl V, Wolin EM, Oberg K, Van Cutsem E, Yao JC; RADIANT-2 Study Group: Everolimus plus octreotide longacting repeatable for the treatment of advanced neuroendocrine tumours associated with carcinoid syndrome (RADIANT-2): a randomised, placebo-controlled, phase 3 study. Lancet 2011;378:20052012.

5 Fazio N, Granberg D, Grossman A, Saletan S, Klimovsky J, Panneerselvam A, Wolin EM: Everolimus plus octreotide long-acting repeatable in patients with advanced lung neuroendocrine tumors: analysis of the phase 3, randomized, placebo-controlled RADIANT-2 study. Chest 2013;143:955-962.

-6 Beck T, Mantooth R: Long-term management of a patient with well-differentiated pulmonary neuroendocrine carcinoma: a case report. Case Rep Oncol 2013;6:209-215.

-7 Granberg D, Eriksson B, Wilander E, Grimfjärd P, Fjällskog ML, Oberg K, Skogseid B: Experience in treatment of metastatic pulmonary carcinoid tumors. Ann Oncol 2001;12:1383-1391.

-8 Broder LR, Carter SK: Pancreatic islet cell carcinoma. Results of therapy with streptozotocin in 52 patients. Ann Intern Med 1973;79:108-118.

-9 Sun W, Lipsitz S, Catalano P, Mailliard JA, Haller DG; Eastern Cooperative Oncology Group: Phase II/III study of doxorubicin with fluorouracil compared with streptozocin with fluorouracil or dacarbazine in the treatment of advanced carcinoid tumors: Eastern Cooperative Oncology Group Study E1281. J Clin Oncol 2005;23:4897-4904.

10 Krug S, Boch M, Daniel H, Nimphius W, Müller D, Michl P, Rinke A, Gress TM: Streptozocin-based chemotherapy in patients with advanced neuroendocrine neoplasms - predictive and prognostic markers for treatment stratification. PLoS One 2015;10:e0143822.

-11 Engstrom PF, Lavin PT, Moertel CG, Folsch E, Douglass HO Jr: Streptozocin plus fluorouracil versus doxorubicin therapy for metastatic carcinoid tumor. J Clin Oncol 1984;2:1255-1259.

-12 Hammel P, Hentic O, Neuzillet C, Faivre S, Raymond E, Ruszniewski P: New treatment options with cytotoxic agents in neuroendocrine tumours. Target Oncol 2012;7:169-172.

-13 Aoki T, Kokudo N, Komoto I, Takaori K, Kimura W, Sano K, Takamoto T, Hashimoto T, Okusaka T, Morizane C, Ito T, Imamura M: Streptozocin chemotherapy for advanced/metastatic well-differentiated neuroendocrine tumors: an analysis of a multi-center survey in Japan. J Gastroenterol 2015;50:769775.

14 Dilz LM, Denecke T, Steffen IG, Prasad V, von Weikersthal LF, Pape UF, Wiedenmann B, Pavel M: Streptozocin/5-fluorouracil chemotherapy is associated with durable response in patients with advanced pancreatic neuroendocrine tumours. Eur J Cancer 2015;51:1253-1262.

15 Moertel CG, Hanley JA, Johnson LA: Streptozocin alone compared with streptozocin plus fluorouracil in the treatment of advanced islet-cell carcinoma. N Engl J Med 1980;303:1189-1194.

16 Hauso 0, Gustafsson BI, Kidd M, Waldum HL, Drozdov I, Chan AK, Modlin IM: Neuroendocrine tumor epidemiology: contrasting Norway and North America. Cancer 2008;113:2655-2664. 


\section{Case Reports in Oncology}

\begin{tabular}{l|l}
\hline Case Rep Oncol 2018;11:49-54 \\
\hline DOI: $10.1159 / 000477163$ & $\begin{array}{l}\text { C } 2018 \text { The Author(s). Published by S. Karger AG, Basel } \\
\text { www.karger.com/cro }\end{array}$ \\
\hline
\end{tabular}

Fukushima et al: Successful Salvage Chemotherapy with Streptozocin in a Patient with Mediastinal Atypical Carcinoid Tumor Who Had Relapsed after Various Prior Therapies

17 Ito T, Igarashi H, Nakamura K, Sasano H, Okusaka T, Takano K, Komoto I, Tanaka M, Imamura M, Jensen RT, Takayanagi R, Shimatsu A: Epidemiological study of gastroenteropancreatic neuroendocrine tumors in Japan. J Gastroenterol 2010;45:234-243.

18 Ito T, Igarashi H, Nakamura K, Sasano H, Okusaka T, Takano K, Komoto I, Tanaka M, Imamura M, Jensen RT, Takayanagi R, Shimatsu A: Epidemiological trends of pancreatic and gastrointestinal neuroendocrine tumors in Japan: a nationwide survey analysis. J Gastroenterol 2015;50:58-64.

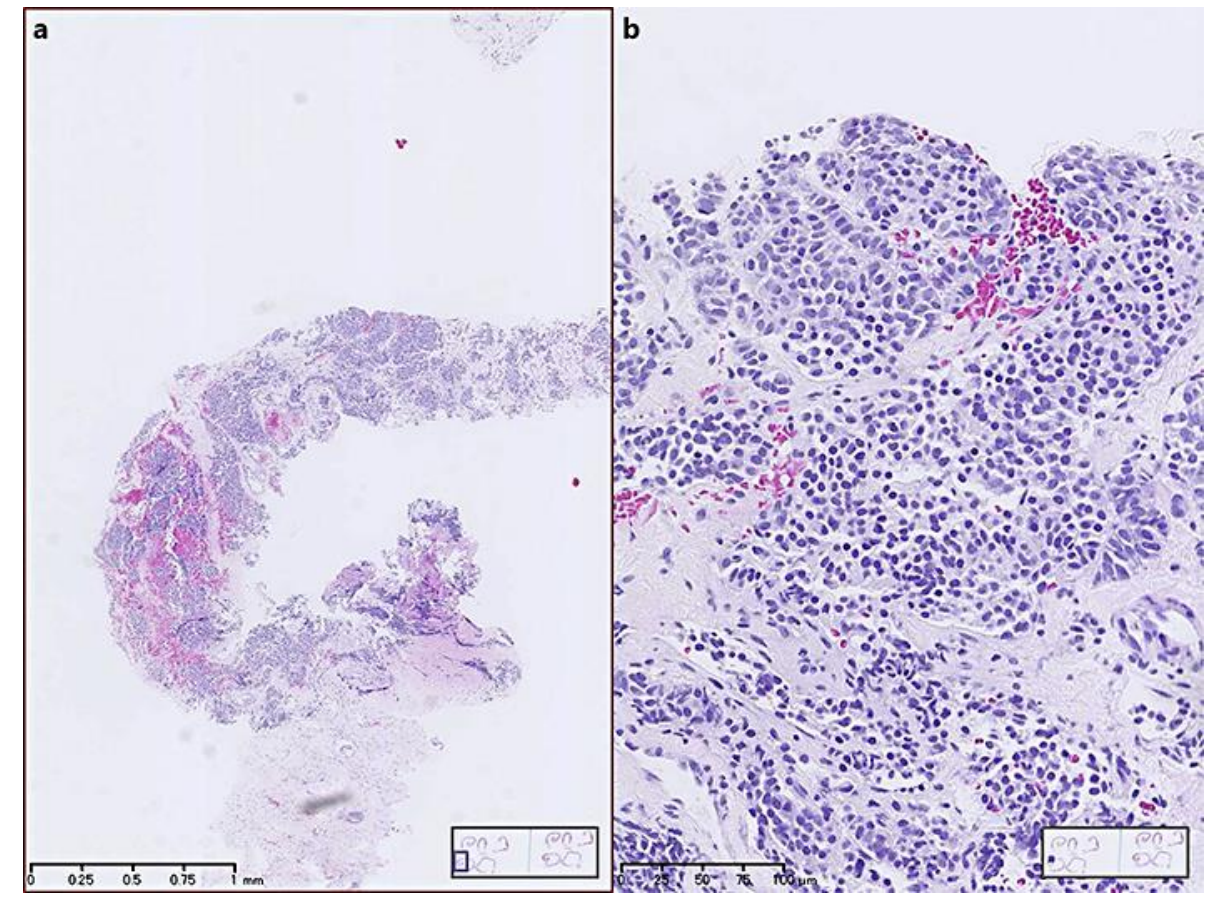

Fig. 1. Histological findings by percutaneous computed tomography biopsy revealed atypical carcinoma cells. a Low-power field. b High-power field. 


\section{Case Reports in Oncology}

\begin{tabular}{l|l}
\hline Case Rep Oncol 2018;11:49-54 \\
\hline DOI: $10.1159 / 000477163$ & $\begin{array}{l}\text { C 2018 The Author(s). Published by S. Karger AG, Basel } \\
\text { www.karger.com/cro }\end{array}$ \\
\hline
\end{tabular}

Fukushima et al.: Successful Salvage Chemotherapy with Streptozocin in a Patient with Mediastinal Atypical Carcinoid Tumor Who Had Relapsed after Various Prior Therapies
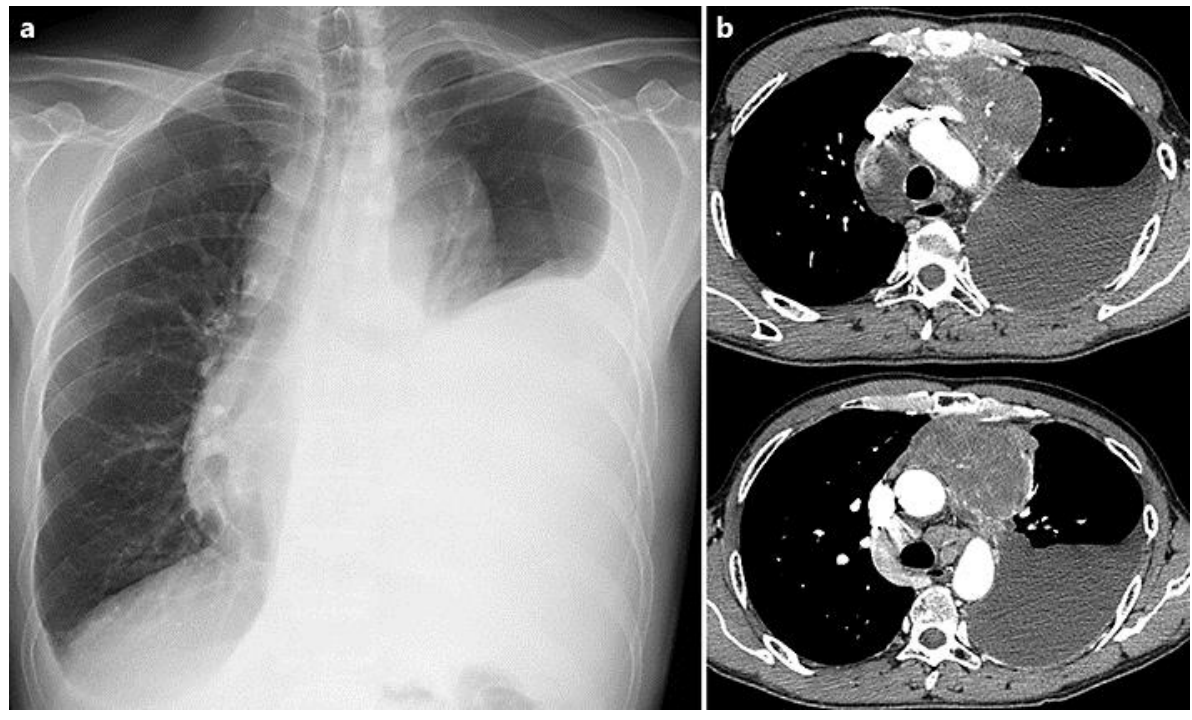

Fig. 2. Chest radiography (a) and computed tomography (b) before streptozocin treatment.
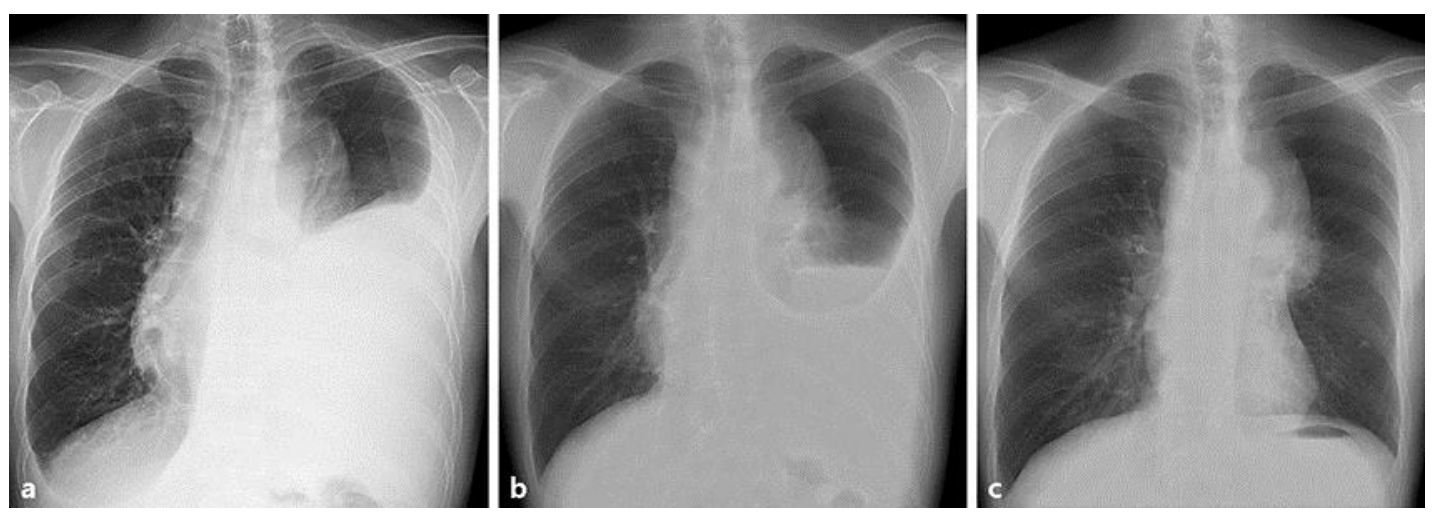

Fig. 3. Serial chest radiographs before (a) as well as 1 month (b) and 4 months (c) after streptozocin treatment. 